OPEN ACCESS

Edited by:

Gillbert Greub,

University of Lausanne, Switzerland

Reviewed by:

Hélène Marquis,

Cornell University, USA

Darren Lee Smith,

University of Northumbria at Newcastle, UK

${ }^{*}$ Correspondence:

Jens A. Hammer

jens-andre.hammerl@bfr.bund.de

Specialty section

This article was submitted to

Virology,

a section of the journal

Frontiers in Microbiology

Received: 15 September 2015

Accepted: 11 January 2016

Published: 28 January 2016

Citation:

Hammerl JA, Göllner C, Al Dahouk S, Nöckler K, Reetz J and Hertwig S

(2016) Analysis of the First Temperate Broad Host Range Brucellaphage

(BiPBO1) Isolated from B. inopinata.

Front. Microbiol. 7:24

doi: 10.3389/fmicb.2016.00024

\section{Analysis of the First Temperate Broad Host Range Brucellaphage (BiPBO1) Isolated from $B$. inopinata}

\author{
Jens A. Hammerl *, Cornelia Göllner, Sascha Al Dahouk, Karsten Nöckler, Jochen Reetz \\ and Stefan Hertwig
}

Department of Biological Safety, Federal Institute for Risk Assessment, Berlin, Germany

Brucella species are important human and animal pathogens. Though, only little is known about mobile genetic elements of these highly pathogenic bacteria. To date, neither plasmids nor temperate phages have been described in brucellae. We analyzed genomic sequences of various reference and type strains and identified a number of putative prophages residing within the Brucella chromosomes. By induction, phage BiPBO1 was isolated from Brucella inopinata. BiPBO1 is a siphovirus that infects several Brucella species including Brucella abortus and Brucella melitensis. Integration of the phage genome occurs adjacent to a tRNA gene in chromosome 1 (chr 1). The bacterial (attB) and phage (attP) attachment sites comprise an identical sequence of $46 \mathrm{bp}$. This sequence exists in many Brucella and Ochrobactrum species. The BiPBO1 genome is composed of a 46,877 bp double-stranded DNA. Eighty-seven putative gene products were determined, of which 32 could be functionally assigned. Strongest similarities were found to a temperate phage residing in the chromosome of Ochrobactrum anthropi ATCC 49188 and to prophages identified in several families belonging to the order rhizobiales. The data suggest that horizontal gene transfer may occur between Brucella and Ochrobactrum and underpin the close relationship of these environmental and pathogenic bacteria.

Keywords: Brucella, phage, genome, temperate, lysogeny, prophage

\section{INTRODUCTION}

Bacteriophages (phages) are viruses which exclusively infect bacteria. They have been found in nearly all known bacterial taxa and hence exist in most ecosystems (Wommack and Colwell, 2000; Prestel et al., 2008; Srinivasiah et al., 2008). Phages are either directly associated with their bacterial hosts or occurring in large numbers as free particles in the environment. The global phage population has been estimated at $10^{31}$ particles, $\sim 10$ times more than their host cells (Hatfull, 2008). Thus, phages are the most abundant biological entities on earth. They play a major role in horizontal gene transfer by either transduction of bacterial genes, which can be provoked by both temperate and virulent phages, or by lysogenic conversion, a change in the properties of a bacterial cell as a result of its infection with a temperate phage (Fortier and Sekulovic, 2013; Brown-Jaque et al., 2015; Penadés et al., 2015). Phage-mediated gene transfer can modulate the virulence of pathogenic bacteria. Many bacterial toxins are encoded by temperate phages, e.g., botulism toxin, cholera toxin, diphtheria toxin, or shiga toxins (Brüssow et al., 2004; Casas and Maloy, 2011). In addition, phages may encode various enzymes important for pathogenicity such 
as phospholipase, staphylokinase, superoxide dismutase, and effector proteins participating in adhesion, invasion, and serum resistance (Boyd and Brüssow, 2002). Prophages are common in bacterial chromosomes and can constitute as much as $10-20 \%$ of a bacterium's genome (Casjens, 2003). Strains containing multiple sequence-related prophages can experience recombinations leading to prophages with new gene constellations (Canchaya et al., 2004). Moreover, prophages can cause large-scale rearrangements of the bacterial chromosome (Iguchi et al., 2006). Though, while temperate phages, some of which encoding virulence factors, have been identified in many pathogenic species, they have yet not been reported for some intracellular pathogens like Coxiella, Rickettsia, and Brucella.

Brucellae are facultative intracellular pathogens that belong to Alphaproteobacteria. The genus Brucella, established in 1920 by Meyer and Shaw, consists of 11 species, which can be divided into the classical Brucella species (B. melitensis, B. abortus, B. suis, B. canis, $B$. ovis, and $B$. neotomae), brucellae isolated from marine mammals (B. ceti and B. pinnipedialis) and the more recently discovered species $B$. microti, B. papionis, and B. inopinata (http://www.bacterio.net/brucella.html). B. inopinata, recovered from a breast implant infection, is currently represented by a single strain (Scholz et al., 2010). All Brucella species are genetically highly related with genome similarities of $>90 \%$ at the nucleotide level. While most Brucella species are fastidious and slow growing with limited metabolic activity, B. microti and $B$. inopinata are fast growing bacteria, with a biochemical profile similar to that of Ochrobactrum (Al Dahouk et al., 2010), the closest genetic neighbor within the family Brucellaceae that shows strong $16 \mathrm{~S}$ rRNA and recA similarities to Brucella (e.g., Ochrobactrum anthropi 98.7 and 85.5\%, respectively, Scholz et al., 2008). Consequently, B. microti and B. inopinata are often misidentified as Ochrobactrum using commercially available biochemical test systems, like e.g., API20NE.

Brucellae can cause brucellosis, a widespread bacterial zoonotic disease (Zheludkov and Tsirelson, 2013) leading to reproductive failure and abortion in animals and a feverish multiorgan disease in humans (Godfroid et al., 2012). The species mainly associated with human infections are $B$. melitensis transmitted from sheep and goats, B. abortus from cattle and $B$. suis from pigs. However, not only livestock but also wildlife can contribute to the spread of this pathogen and may pose a risk (Zheludkov and Tsirelson, 2013; Hammerl et al., 2015). The adaption of brucellae to the intracellular lifestyle within a specific host is known to be associated with genome reduction (Teyssier et al., 2004). Genes not necessary for survival in the intra-host environment are lost. In contrast, the exchange and acquisition of genetic material is essential for free-living bacteria in water and soil which have to struggle against changing conditions. With the discovery of various new and atypical Brucella species, the evolution from a soil progenitor to a highly pathogenic intracellular bacterium is broadly discussed (Wattam et al., 2014). Lateral gene transfer is supposed to be responsible for the introduction of virulence factors into Brucella, but underlying mechanisms have not yet been identified. Numerous genes presumably important for survival and virulence have been detected in the chromosomes of B. abortus, B. melitensis, and B. suis; some of them are located on genomic islands (Delrue et al., 2004). By contrast, neither plasmids nor temperate phages have to date been isolated from Brucella, even though virulent Brucella phages devoid of virulence-associated genes are routinely employed for typing. The history of brucellaphages and their use as diagnostic tool for the identification of Brucella species began with the discovery of phage $\mathrm{Tb}$ (Tbilisi, Russia) in the 1960s (Corbel and Phillip, 1972; Corbel and Thomas, 1976; Thomas and Corbel, 1977). Some phages were isolated from Brucella cultures but lysogeny has not yet been demonstrated. On the basis of their host range, brucellaphages are classified in seven groups ( $\mathrm{Tb}, \mathrm{Fi}, \mathrm{Wb}, \mathrm{Bk} 2, \mathrm{R} / \mathrm{C}, \mathrm{Iz}, \mathrm{Np}$, Alton et al., 1975; Ackermann et al., 1981; Corbel, 1987). All brucellaphages described so far have a podoviral morphology and are closely related (Flores et al., 2012; Farlow et al., 2014). They are considered as a single taxonomic species comprising different host range variants (Corbel and Thomas, 1976; Ackermann et al., 1981). Analyses of whole genome sequences of Brucella strains imply that temperate phages might also occur in this genus since prophage DNA has been detected in some of the investigated strains. The genome of a putative prophage of Roseobacter has e.g., been found in B. canis SVA13 (Kaden et al., 2014a,b). However, there is yet no information available on the integrity of the phage. The hitherto identified prophage sequences in Brucella might be remnants of formerly intact phage genomes that were lost on the way of the bacteria from soil to mammalian hosts.

The goal of this study was to ascertain, whether intact prophages exist in Brucella. To accomplish this, the prophage content of numerous Brucella reference and type strains has been determined by in silico analyses. Induction experiments were carried out to release phage particles from the bacteria. By doing this, the temperate phage BiPBO1 was isolated from $B$. inopinata and characterized in terms of its phenotypic and genotypic properties.

\section{MATERIALS AND METHODS}

\section{Bacterial Strains, Media, and Growth Conditions}

All strains used in this study are listed in Table S1. If not stated otherwise, Brucella strains were cultivated in Brucella-broth (Carl Roth, Karlsruhe, Germany) under microaerobic conditions (10\% $\mathrm{CO}_{2}$ ) according to standard procedures. For the cultivation of B. ovis, the medium was supplemented with $10 \%$ horse serum (Alton et al., 1975). Solid and overlay agar contained $1.8 \%$ and $0.7 \%$ (w/v) bacto-agar No. 1 (Oxoid, Wesel, Germany), respectively.

\section{Prophage Induction Experiments}

To study phage release from brucellae, several stress conditions (mitomycin $\mathrm{C}$ treatment, high temperatures, and $\mathrm{UV}$ radiation) were applied. At a McFarland of $0.8-1.2,12.5 \mu \mathrm{g} / \mathrm{ml}^{-1}$ mitomycin $\mathrm{C}$, heat treatment at 60,70 , or $80^{\circ} \mathrm{C}$ (for 30 and $60 \mathrm{~s}$ ), or UV radiation (for 30,60, and $120 \mathrm{~s}$ ) were applied and cultivation of the bacteria was continued for $16 \mathrm{~h}$ without shaking. Induction via UV treatment was performed by pouring 
an aliquot of the Brucella culture into a sterile petri dish $(d=$ $90 \mathrm{~mm}$ ). The dish was placed in a distance of $10 \mathrm{~cm}$ to the UV lamp (corresponding $45 \mathrm{~J} \mathrm{~m}^{-2}$ ) followed by radiation for different time periods. All strains were investigated in triplicate under the respective induction conditions. Lytic activity caused by induced phages was determined as stated below.

\section{Isolation, Propagation, and Purification of BiPBO1}

Phage BiPBO1 was recovered by mitomycin $C$ treatment of $B$. inopinata strain BO1 (Scholz et al., 2010). Bacteria-free phage lysates were obtained by centrifugation at $6000 \mathrm{~g}$ for $15 \mathrm{~min}$ and filtration of the supernatant through $0.45 \mu \mathrm{m}$ and $0.22 \mu \mathrm{m}$ sterile filters (GE Healthcare, Munich, Germany). Lytic activity was detected by spotting $10 \mu \mathrm{l}$ aliquots of a 1:10 dilution series of lysates onto lawns of Brucella indicator strains (Viazis et al., 2011). To determine phage titers, the softagar overlay method was applied (Sambrook and Russel, 2001). BiPB01 isolation was achieved by three-fold repetition of single plaque assays using $B$. abortus S19 as host. High-titer lysates were obtained by infecting five $100 \mathrm{ml}$ cultures of $B$. abortus S19 (McFarland 3.0-4.0) with BiPBO1 at a multiplicity of infection (MOI) of 0.1 . The lysates were prepared as stated above. After filtration, $10 \mathrm{mM} \mathrm{MgCl}_{2}$, $10 \mu \mathrm{g} \mathrm{ml}^{-1}$ DNaseI, and RNase A (Roche, Mannheim, Germany) were added to the lysates which were incubated at $37^{\circ} \mathrm{C}$ for $2 \mathrm{~h}$. Phage particles were concentrated using Vivaspin ${ }^{\circledR} 20$ columns as recommended by the manufacturer (Sartorius, Goettingen, Germany). Concentrated phages were purified by discontinuous gradient centrifugation (at 141,000 $\times \mathrm{g}$ for $18 \mathrm{~h}$ ) using caesium chloride (CsCl, 1.3-1.7 $\mathrm{g} \mathrm{ml}^{-1}$ ) (Sambrook and Russel, 2001). Phage bands were collected from centrifugation tubes using a syringe and desalted by $100 \mathrm{~K}$ Amicon Ultra centrifugal filter columns (Merck Millipore, Schwalbach, Germany).

\section{Determination of the Host Range}

The host range of BiPBO1 and of two virulent reference phages F1 and F25 as a control (Table S2) was determined by spot activity assays (Viazis et al., 2011). F1 and F25 are routinely used in our institute for Brucella typing (Al Dahouk et al., 2012). Sequence analysis of $\mathrm{F} 1$ revealed that it is a close relative of phage Tbilisi (Hammerl et al., 2014). Two hundred microliters of each Brucella strain were mixed with $5 \mathrm{ml}$ of pre-warmed Brucella-broth soft agar (0.7\%) and poured onto a Brucella agar plate. Ten microliters aliquots of 1:10 serial dilutions of BiPBO1 lysates were spotted onto the overlay agar. Agar plates were visually inspected after incubation for 24 and $48 \mathrm{~h}$ at $37^{\circ} \mathrm{C}$. Phage activity was analyzed on 26 Brucella reference and type strains as well as on 119 Ochrobactrum, seven Yersinia enterocolitica O:9, six Mesorhizobium, five Sinorhizobium, and five Pseudomonas strains.

\section{Lysogenisaton of $B$. abortus S19}

The ability of BiPBO1 to lysogenize B. abortus S19 was investigated by isolation of bacteria from lysis zones. The respective area of the soft agar was removed and bacteria were eluted in PBS buffer. One hundred microliters aliquots of 1:10 dilution series of the bacterial suspensions were plated on Brucella agar and incubated for $48^{\circ} \mathrm{h}$ at $37^{\circ} \mathrm{C}$. Altogether 50 colonies were investigated in terms of immunity against superinfection with $\mathrm{BiPBO}$. This was performed by spot assays as described above. The non-treated B. abortus S19 strain was used as control to demonstrate lytic activity. Colonies identified as phage resistant were further screened for phage release by induction with mitomycin C. Positive colonies were selected for further analyses. The stability of lysogeny was investigated by cultivation of the lysogens over 50-100 generations.

\section{Phage Curing}

Curing was examined by treating the lysogenic strains $B$. inopinata $\mathrm{BO} 1$ and $B$. abortus $\mathrm{S} 191 \mathrm{lys} \mathrm{BPBO} 1$ with acridine orange (final concentration $0.1,0.05$, and $0.01 \mathrm{mM}$ ). At a McFarland of $0.8-1.2$, acridine orange was applied and cultivation was continued for $16 \mathrm{~h}$ without shaking. Thereafter, 1:10 dilution series of the treated cultures were plated on Brucella agar and cultivated as stated above (Hammerl et al., 2008). Colonies from selected dilutions were analyzed for BiPBO1 phage activity (see above) and by Multiplex-PCR using primers deduced from the genes for the integrase (ORF37), major capsid protein (ORF06), and replication protein (ORF79, Table S5).

\section{Phenotypic Profiling via Micronaut ${ }^{\mathrm{TM}}$}

Differences in the phenotypic profile (metabolization of various substrates) between B. abortus S19 (phage-free) and B. abortus S19lysBiPBO1 were investigated as previously described ( $\mathrm{Al}$ Dahouk et al., 2010). Final data are based on results of three independent experiments.

\section{PCR Analyses}

PCR reactions were performed in an Eppendorf Mastercycler ep Gradient (Eppendorf, Hamburg, Germany) according to standard protocols. Single reactions were carried out in a final volume of $25 \mu \mathrm{l}$ by use of DreamTaq DNA polymerase amplification components (Fisher Scientific, Schwerte, Germany). The mastermix of a reaction comprised $9.0 \mu \mathrm{l}$ RNase-free water, $2.5 \mu \mathrm{l} 10 \times$ DreamTaq buffer, $2.5 \mu \mathrm{l}$ dNTP solution $(2 \mathrm{mM}), 6.5 \mu \mathrm{l}$ of DreamTaq Enzyme, $2.5 \mu \mathrm{l}$ of each primer, and $2.0 \mu \mathrm{l}$ of template DNA $(\sim 10 \mathrm{ng} / \mu \mathrm{l})$. Primers were designed by means of Accelrys Gene v2.5 (Accelrys Inc., San Diego, CA, USA) using default parameters. For the detection of prophage DNA by Multiplex-PCR, reactions started with activation and template denaturation at $94^{\circ} \mathrm{C}$ for $120 \mathrm{~s}$ followed by 35 cycles (denaturation at $94^{\circ} \mathrm{C}$ for $15 \mathrm{~s}$, annealing at $58^{\circ} \mathrm{C}$ for $15 \mathrm{~s}$, and elongation for $60 \mathrm{~s}$ at $72^{\circ} \mathrm{C}$ ). In addition, a final elongation step at $72^{\circ} \mathrm{C}$ for $1 \mathrm{~min}$ was performed before the PCR reactions were stored at $4^{\circ} \mathrm{C}$ until further processing. For the determination of the chromosomal integration site, the annealing temperature and the elongation time were modified to $55^{\circ} \mathrm{C}$ and $120 \mathrm{~s}$, respectively.

\section{Determination of the Integration Site}

To determine the chromosomal integration site of the phage, gDNA of B. inopinata BO1 and B. abortus S19lysBiPBO1 was isolated using the DNA mini preparation kit (Qiagen, Hilden, Germany). The DNAs were digested with several restriction 
endonucleases (Bsp143I, DpnI, DraI, Eco32I, HindIII) according to the manufacturer's recommendations (Fermentas, St. Leon Roth, Germany). Restriction fragments of each digest were treated with T4 ligase (Fermentas) and used as template in a PCR reaction applying outward facing primers deduced from the coding region of the BiPBO1 integrase gene (Table S5). PCR products were purified (QIAquick PCR purification kit, Qiagen) and sequenced. The obtained nucleotide sequences of the amplicons were compared with whole genome sequences of the respective strains. To study the BiPB01 integration site in other Brucella strains, a Multiplex-PCR was developed. Primers deduced from the Brucella chromosome left and right of the BiPB01 integration site provided information on the presence of foreign DNA at this position. Combinations of these primers with primers deduced from the BiPB01 genome were used to detect BiPB01-related prophage DNA. All primers are listed in Supplementary Material Table S5.

\section{SDS-PAGE and Mass Spectrometrical Analysis of Structural Proteins}

The composition of structural proteins of CsCl-purified phage particles was investigated by Coomassie stained SDS-PAGE according to standard procedures. Protein bands were excised and prepared for tryptic in gel-digests as previously described (Hammerl et al., 2011). The prepared samples were investigated by MALDI-TOF-TOF MS/MS analysis. Mass spectra were interpreted using the Mascot software and NCBI database.

\section{Transmission Electron Microscopy}

CsCl-purified phages were applied to pioloform-carbon-coated, 400-mesh copper grids (Plano GmbH, Germany), for $7 \mathrm{~min}$, fixed with $2.5 \%$ aqueous glutaraldehyde solution for $1 \mathrm{~min}$, stained with $2 \%$ aqueous uranyl acetate solution for $1 \mathrm{~min}$ and examined by transmission electron microscopy using a JEM-1010 (JOEL, Japan) at $80 \mathrm{kV}$ accelerated voltage.

\section{Extraction of Phage DNA and Sequencing}

Phage DNA was extracted from CsCl-purified particles by proteinaseK/SDS treatment followed by phenol/chloroform extraction and ethanol precipitation (Sambrook and Russel, 2001). Thereafter, the phage DNA was resuspended in $0.5 \times$ TE-buffer ( $\mathrm{pH}$ 8.0) for further analyses.

Whole-genome sequencing was performed with the Roche 454 genome sequencer FLX titanium system by LGC Genomics (Berlin, Germany). Library generation for 454 FLX sequencing was carried out according to the manufacturer's standard protocols (Roche/454 Life Sciences, Branford, Connecticut, USA). Phage DNA was sheared by nebulization into fragments between 500 and 1000 bp. Fragments were end-polished and the required adaptors for sequencing were ligated to the ends of the fragments. Sequencing was performed on 1/16 picotiterplate (PTP) on the GS FLX using Roche/454 Titanium chemistry. Sequence reads were assembled using the Roche/454 Newbler software at default settings (454 Life Sciences Corporation, Software release 2.3) resulting in one contig with an average sequence coverage of more than 90 per consensus base.

\section{Bioinformatic Analysis}

To identify putative prophage sequences in the available Brucella spp. genomes of GenBank (NCBI), the Phage Search ToolPHAST was used (Zhou et al., 2011). Sequence analysis and alignments were carried out using Accelrys Gene v2.5 (Accelrys Inc., San Diego, CA, USA). ORF analyses were performed using the algorithms of MyRAST (Aziz et al., 2008; Meyer et al., 2008; Glass et al., 2010) and ORF Finder (NCBI) (gene product size $>29$ aa, Rombel et al., 2002). Similarity and identity values were determined at the NCBI homepage using the standard parameters of different BLAST algorithms (Johnson et al., 2008). Transcription terminators were identified using TransTerm (Brown et al., 1993; Ermolaeva et al., 2000) and Arnold (Naville et al., 2011). If not stated otherwise, standard parameter of the respective algorithms were used.

\section{Nucleotide Sequence Accession Number}

The complete nucleotide sequence of the BiPBO1 genome was submitted to GenBank under the accession number KT724718.

\section{RESULTS}

\section{Prophages are Common in Brucella}

In this in silico study we wanted to gather information about the occurrence of prophage sequences within the genus Brucella. Using the PHAST computer program, various sequenced Brucella reference and type strains (Table 1) were analyzed. Except for the $B$. inopinata strain BO1, which has only partially be sequenced (WGS), all studied Brucella strains exhibited putative prophage DNA. Up to four individual prophage regions between 7.7 and $83.1 \mathrm{~kb}$ in size were identified within each genome (Table 1). Highly prevalent was a very similar $9.7-13.7 \mathrm{~kb}$ region that we found in many Brucella species. This DNA region revealed strong homologies to the virulent phage P12026 of the marine bacterium Marinomonas (Kang et al., 2012). Next frequently, a DNA region of $9.5-83.1 \mathrm{~kb}$ was detected in six Brucella species showing relationship to a prophage already identified in the B. suis strain 1330 (Paulsen et al., 2002). In contrast to these prophage DNAs existing in several Brucella species, only the three investigated $B$. melitensis strains contained a putative prophage related to the Trichoplusia $n i$ ascovirus $2 \mathrm{c}$ that causes chronic disease in lepidopteran larvae (Wang et al., 2006) Prophage DNA similar to the virulent Roseobacter denitrificans phage RDJLPhi1 (Zhang and Jiao, 2009) was exclusively detected in $B$. ceti, while B. abortus 544 contains prophage sequences similar to the giant moumouvirus isolated from the protozoa Acanthamoeba polyphaga (Yoosuf et al., 2012). Finally, four prophage DNA regions related to phages or prophages of Marinomonas, Pseudomonas, Rhodobacter, and E. coli were found in the B. inopinata-like strain $\mathrm{BO} 2$.

\section{Isolation of the Temperate Phage BiPBO1}

To elucidate whether the identified prophage regions represent active phages, one member of each species (B. abortus S19, B. melitensis $63 / 9$, B. ovis $63 / 290$, and the B. inopinata-like strain $\mathrm{BO} 2$ ) harboring various numbers of putative prophages 
TABLE 1 | Prophage sequences in Brucella determined by in silico analysis (PHAST).

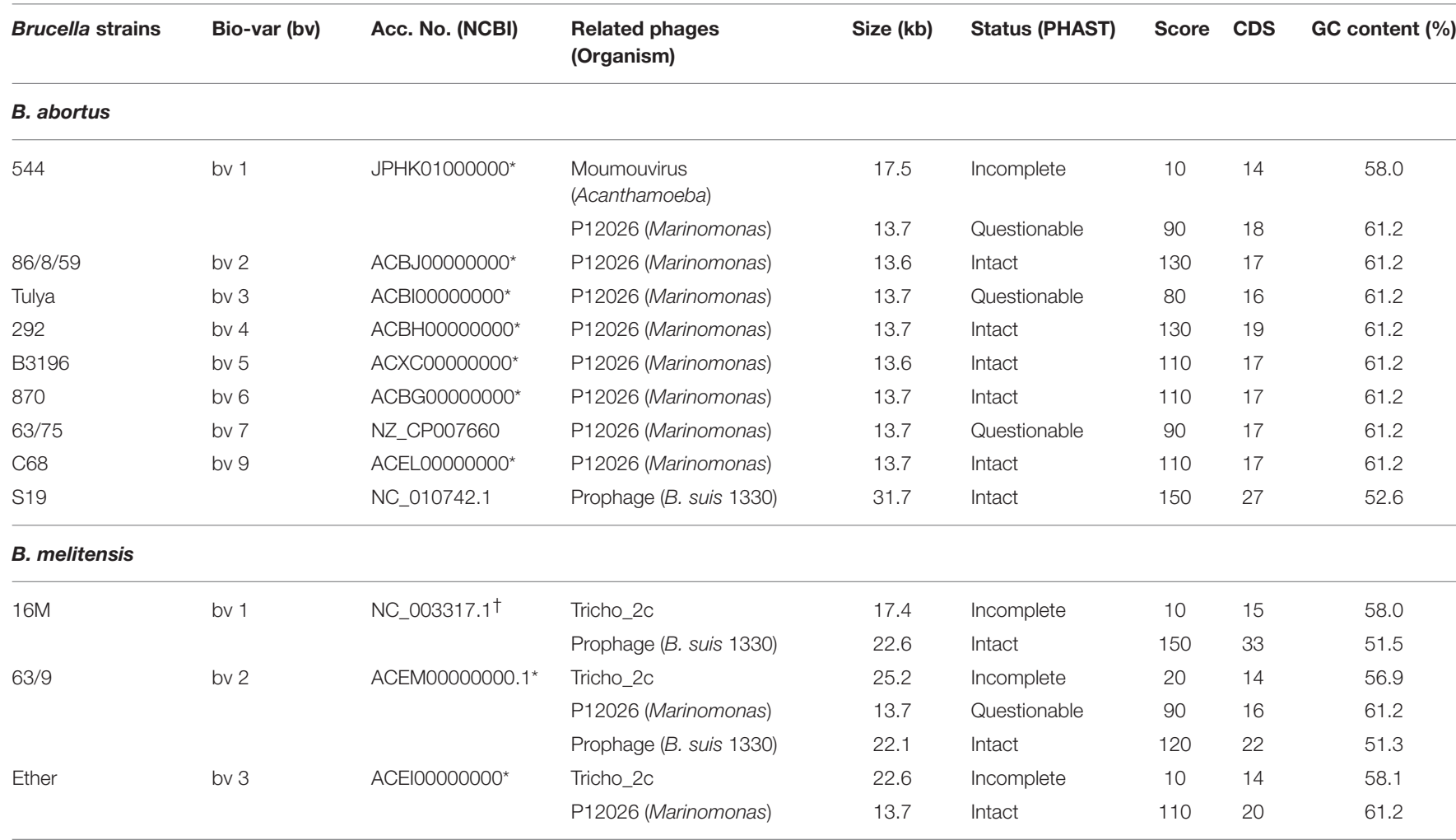

\section{B. suis}

\begin{tabular}{|c|c|c|c|c|c|c|c|c|}
\hline 1330 & bv 1 & NC_004310.3 ${ }^{\dagger}$ & P12026 (Marinomonas) & 9.7 & Questionable & 90 & 15 & 61.0 \\
\hline Thomsen & bv 2 & NC_004311. $2^{\dagger}$ & Prophage (B. suis 1330) & 31.8 & Intact & 150 & 28 & 52.7 \\
\hline 686 & bv 3 & ACBL00000000* & P12026 (Marinomonas) & 13.7 & Intact & 110 & 19 & 61.2 \\
\hline 513 & bv 5 & ACBK00000000* & P12026 (Marinomonas) & 13.7 & Intact & 110 & 19 & 61.3 \\
\hline
\end{tabular}

\section{B. canis}

\begin{tabular}{|c|c|c|c|c|c|c|c|}
\hline \multirow[t]{2}{*}{$\mathrm{RM}$ 6/66 } & \multirow[t]{2}{*}{ NC_010103.1 ${ }^{\dagger}$} & P12026 (Marinomonas) & 9.8 & Questionable & 90 & 16 & 61.0 \\
\hline & & Prophage (B. suis 1330) & 41.3 & Intact & 150 & 32 & 54.2 \\
\hline \multicolumn{8}{|c|}{ B. neotomae } \\
\hline \multirow[t]{2}{*}{5 КЗ33 } & ACEHO0000000* & P12026 (Marinomonas) & 13.7 & Questionable & 90 & 17 & 61.4 \\
\hline & & Prophage (B. suis 1330) & 21.7 & Intact & 100 & 23 & 51.4 \\
\hline \multirow[t]{2}{*}{$63 / 290$} & NC_009505.1 ${ }^{\dagger}$ & Prophage (B. suis 1330) & 82.8 & Intact & 150 & 71 & 56.4 \\
\hline & NC_009504.1 ${ }^{\dagger}$ & Prophage (B. suis 1330) & 10.6 & Intact & 110 & 13 & 55.2 \\
\hline \multicolumn{8}{|l|}{ B. ceti } \\
\hline \multirow{2}{*}{ B2/94 } & & Prophage (B. suis 1330) & 31.1 & Intact & 150 & 29 & 52.7 \\
\hline & NC_015858.1 $1^{\dagger}$ & Prophage (B. suis 1330) & 9.5 & Questionable & 80 & 9 & 55.1 \\
\hline
\end{tabular}


TABLE 1 | Continued

\begin{tabular}{|c|c|c|c|c|c|c|c|c|}
\hline Brucella strains & Bio-var (bv) & Acc. No. (NCBI) & $\begin{array}{l}\text { Related phages } \\
\text { (Organism) }\end{array}$ & Size (kb) & Status (PHAST) & Score & CDS & GC content (\%) \\
\hline \multicolumn{9}{|l|}{ B. microti } \\
\hline CCM 4915 T & & NC_013119.1 ${ }^{\dagger}$ & Prophage (B. suis 1330) & 83.1 & Intact & 150 & 79 & 56.5 \\
\hline \multicolumn{9}{|l|}{ B. inopinata } \\
\hline BO1 & & ADEZ00000000.1* & None & - & - & - & - & - \\
\hline \multirow[t]{4}{*}{ BO2 } & & ADFA00000000. $1^{*}$ & P12026 (Marinomonas) & 13.6 & Questionable & 80 & 16 & 61.2 \\
\hline & & & PAJU2 (Pseudomonas) & 20.6 & Incomplete & 50 & 7 & 53.5 \\
\hline & & & RcapMu (Rhodobacter) & 7.7 & Incomplete & 40 & 8 & 56.9 \\
\hline & & & Prophage (E. coli Sakai) & 17.4 & Questionable & 70 & 12 & 55.7 \\
\hline
\end{tabular}

*whole genome shotgun sequence.

†complete genome.

(Table 1) was selected for induction experiments. In addition, $B$. inopinata $\mathrm{BO} 1$ was investigated because it is to date the only strain belonging to this species, even though it has not been completely sequenced thus far.

Prophage induction was studied by treatment of the bacteria with mitomycin C, UV and heat. Using a broad range of indicator strains belonging to several species (Table S1), no lytic activity was observed with lysates prepared from brucellae, in which prophage DNA had been detected by PHAST analysis. However, against all odds, lysates of the B. inopinata strain BO1, in which no prophage DNA was detected by in silico analysis, revealed phage-induced lysis on some Brucella strains. The highest phage titers were obtained using mitomycin $\mathrm{C}\left(5 \times 10^{7} \mathrm{pfu} / \mathrm{ml}\right)$ while UV treatment for $60-120 \mathrm{~s}$ and heat treatment at $50-90^{\circ} \mathrm{C}$ resulted in titers of $10^{5}-10^{6} \mathrm{pfu} / \mathrm{ml}$ and $\sim 5 \times 10^{3} \mathrm{pfu} / \mathrm{ml}$, respectively (Figure 1). Plaques produced by this phage named BiPBO1 had a similar turbidity like those produced by the virulent phages $\mathrm{F} 1$ and F25 but were smaller in size (1-2 mm, Figure 2).

\section{BiPBO1 is a Siphovirus with a Broad Host Range}

Figure 3 shows transmission electronic micrographs of phage BiPBO1. Unlike the virulent Brucella phages that have hitherto been described and that are all typical podoviruses (Ackermann et al., 1981), the temperate phage BiPBO1 is clearly a member of the family Siphoviridae. It possesses an isometric head and a long, non-contractile tail $(203 \times 8 \mathrm{~nm})$. It is the first siphovirus isolated from Brucella.

The host range of BiPBO1 was determined by testing a large number of brucellae and also strains belonging to other genera. BiPBO1 lysed the Brucella species B. abortus, B. melitensis, B. suis B. microti, B. pinnipedialis and a novel Brucella species isolated from red foxes (Table 2), whereas strains of Ochrobactrum $(n=$ 119), Y. enterocolitica O:9 $(n=7)$, Mesorihzobium $(n=6)$, Sinorhizobium $(n=5)$, and Pseudomonas $(n=5)$ were not infected (data not shown). Since the phage's host specificity diverges from those of the virulent Brucella reference phages F1 and F25 (Table 2), BiPBO1 may be useful for typing. Similar to F1 and $\mathrm{F} 25$, BiPBO1 provoked growth inhibition on some indicator strains which was not associated with replication of the phage but rather caused by lysis from without (Abedon, 2011).

To study the stability of lysogeny, B. abortus S19 was lysogenized with phage BiPBO1. Thereafter, we tried to cure the lysogenized $\mathrm{S} 19$ derivative and also the BiPBO1 host strain $B$. inopinata $\mathrm{BO} 1$ using various concentrations of acridine orange and mitomycin C. Altogether, 350 and 75 colonies of B. inopinata BO1 and the lysogenized B. abortus S19 strain, respectively, isolated after treatment with the mutagens were tested for susceptibility to BiPBO1. None of the isolates was lysed by the phage. Moreover, the BiPBO1 prophage was detected in all isolates by Multiplex-PCR and lytic particles were released from them upon induction with mitomycin $\mathrm{C}$ (data not shown). These data demonstrate a strong lysogenic stability of the investigated strains.

\section{Genome Analysis of the Phage}

For the isolation of BiPBO1 DNA, mass lysates originating from single plaques were concentrated and purified by CsCl-buoyant density centrifugation. Interestingly, we failed to precipitate high titres of phages by ultracentrifugation, even at high $g$ values, since only tiny pellets were obtained that quickly cleared away. Therefore, particles were concentrated using Vivaspin ${ }^{\circledR}$ 20 membrane filter units. Sequencing of purified phage DNA resulted in a single contig of $46,877 \mathrm{bp}$. Bioinformatic analyses revealed 87 open reading frames (ORFs), 48 on one (plus-) strand and 39 genes on the other (minus-strand, Table S3). In addition, 19 possible transcription terminators were found, of which 11 are located on the plus-, and eight on the minus-strand (Table S4). Thirty-two of the deduced gene products could be functionally assigned, while 24 of the remaining hypothetical products did not match with any other gene sequence deposited in the NCBI database. An alignment with available sequences of $B$. inopinata $\mathrm{BO} 1$ revealed that only partial sequences of the 


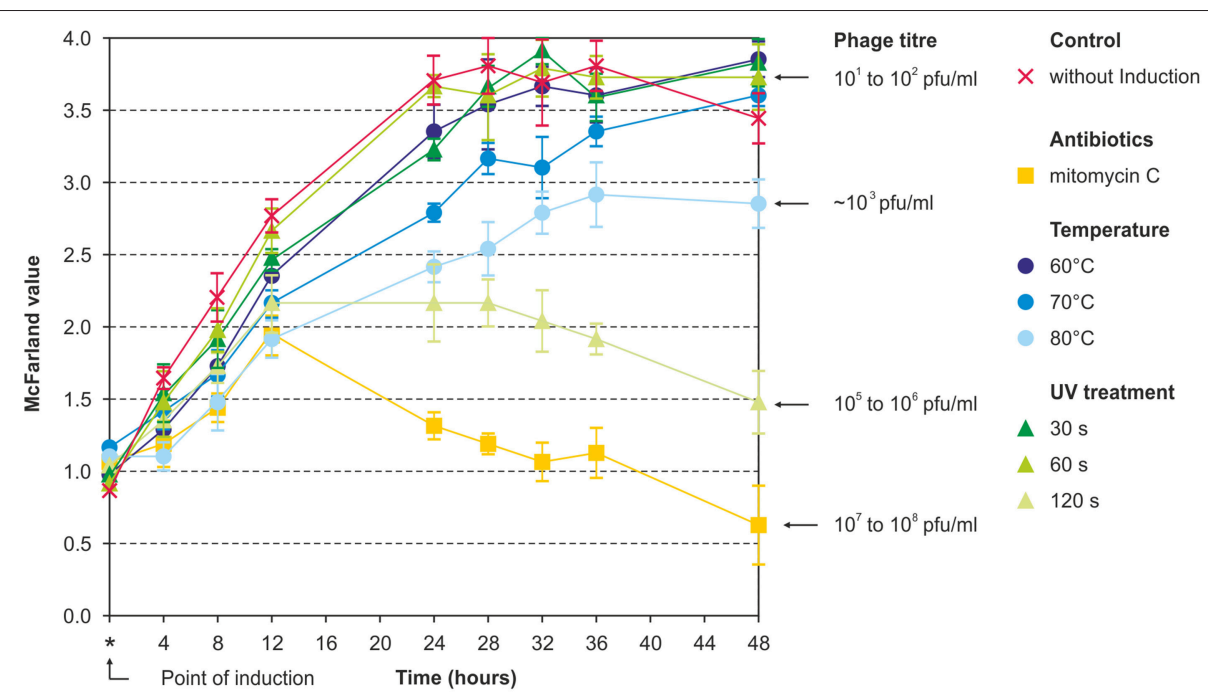

FIGURE 1 | Induction of BiPBO1 by mitomycin C, temperature, and UV. Highest phage titers were obtained by mitomycin C, UV treatment for 120 s and heat treatment at $80^{\circ} \mathrm{C}$. The diagram shows the mean value of three independent experiments. Error bars indicate standard deviations from the mean value.
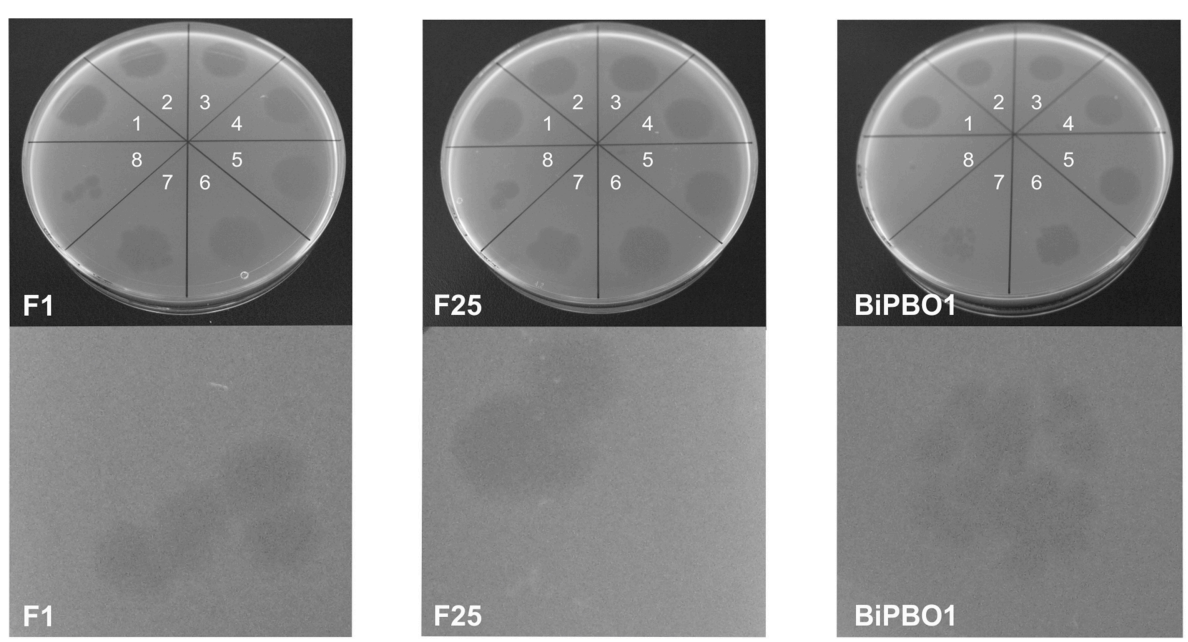

FIGURE 2 | Lytic activity of the phages B01BiPBO1, F1, and F25. The upper panels show spot assays (spot 1 to 8: 1:10 dilution series of the phage lysates) on B. abortus strain $\mathrm{S} 19$. The lower panels show single plaques magnified by a stereo microscope (five-fold magnification).

BiPBO1 genome are covered by contigs of its host strain. Highest similarities were found to a putative prophage in chromosome 1 of O. anthropi strain ATCC 49188 (Figure 4). At the nucleotide level, $26 \%$ of the BiPBO1 genome are more than $90 \%$ identical to this prophage. Lower identity values were determined to other prophage proteins of Brucella, Mesorhizobium, Ochrobactrum, and Sinorhizobium and to some phage proteins as well (Table S3). The obtained data enabled us to construct a BiPBO1 gene map (Figure 5). The map shows that, similar to many other temperate phages, genes probably encoding structural proteins mainly reside in the left half of the genome while genes for integration and host cell lysis are located in the middle and genes involved in replication and immunity at the right end.
The first two ORFs (ORF01 and 02) probably code for the small and large subunit of the terminase. Their products are similar to many terminases encoded by prophages and also to the terminases of the Pseudomonas aeroginosa phage D3 (Kropinski, 2000) and Enterobacteria phage SfV (Allison et al., 2002), which possess cohesive ends. Though, restriction analyses and direct sequencing of BiPBO1 DNA did not give any indication for cohesive ends (data not shown). Two of the next ORFs may encode the portal protein (ORF03) and the major capsid protein (ORF06) that are related to head proteins of HK97-like phages. Adjacent to these ORFs, four putative tail genes (ORF09, 10, 13, and 16) were identified. ORF16 whose product is similar to tape measure proteins, is the largest ORF on the genome. All predicted structural genes of the phage are located on the plus-strand. 

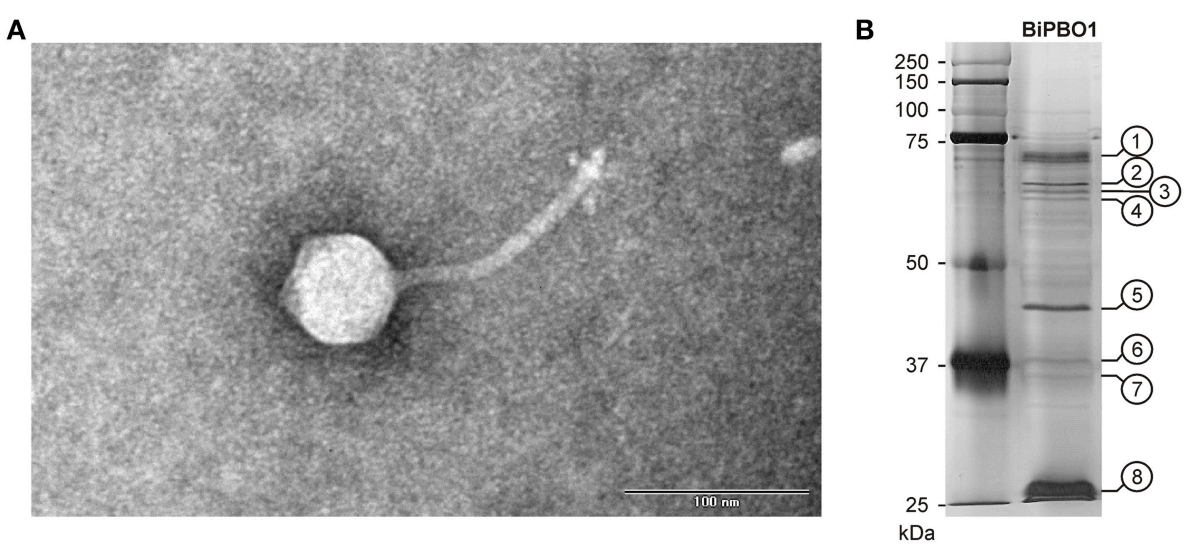

FIGURE 3 | Morphology and structural proteins of BiPBO1. (A) Transmission electron micrograph (TEM) of a BiPBO1 particle isolated from B. inopinata strain BO1 by mitomycin $\mathrm{C}$ induction. The black bar represents a quantification standard of $100 \mathrm{~nm}$. (B) SDS-PAGE profile of BiPBO1 structural proteins. Excised bands that were analyzed by mass spectrometry are numbered.

Embedded in this part of the genome are also two genes located on the minus-strand probably encoding an addiction system composed of a toxin (20) and an antidote protein (ORF19). This module might be responsible for the observed stability of the BiPBO1 prophage. Downstream of the tail genes an ORF (ORF29) for a hypothetical protein was detected, which contains a fibronectin type 3 repeat (FN3). This domain is frequently found in tail proteins of phages and may aid in the attachment of the phage to the cell surface (Fraser et al., 2006). Interestingly, almost identical ORF29 homologs exist in many Brucella strains including strains that are susceptible to BiPBO1. The $\sim 1.5 \mathrm{~kb}$ block within the Brucella genome also encompasses a sequence homologous to a part of BiPB01 ORF30 encoding a pectine lyase. Such enzymes are commonly encoded by bacteria using plant materials of the digestive tract of their hosts as a carbon source (Hugouvieux-Cotte-Pattat et al., 2012). Since ORF29 and ORF 30 are located in the vicinity of attP and the phage integrase gene (see below), the question arises whether these sequences are involved in integration.

The middle of the phage genome harbors numerous small ORFs with unknown functions. Two ORFs in this DNAregion probably represent genes for a phage lysin (ORF33) and the integrase (ORF37). Whether the predicted ORF32 product (a membrane acyltransferase) acts as a holin, has still to be unraveled. As with many other $\mathrm{BiPBO}$ gene products, homologies were found to bacterial proteins, but not to proteins encoded by distinct phages. In the right part of the phage genome several ORFs were identified that may be important for replication. The products of ORF77 and ORF79 are similar to a DnaA initiator protein and DnaB helicase, respectively. A second helicase may be encoded by ORF52. This gene is surrounded by an endonuclease gene (ORF51) and a gene for an exonuclease (ORF53). Besides genes probably involved in replication, this part of the genome may also contain the genetic switch of the phage. The ORF68 product is similar to prophage repressors. Close to the start codon of this ORF, the ORF69 start codon is situated on the other DNA strand. The arrangement of the ORFs 68 and 69 is reminiscent of $c I$ and cro repressor genes but the ORF68 product did not show similarities to Cro repressors. Moreover, operator sites could not be predicted by in silico methods. Summing up, the analysis of the BiPBO1 genome revealed a number of ORFs which are probably essential for the propagation of the phage. On the other hand, most of the remaining genes could not be functionally assigned.

\section{The BiPB01 Attachment Site is Widely Distributed in Brucella and Ochrobactrum}

In this set of experiments the BiPBO1 integration locus within the Brucella chromosome was characterized. In addition, we studied physiological changes that might arise through lysogenization. To determine the bacterial (attB) and phage (attP) attachment sequences, chromosomal DNA was isolated from the B. inopinata strain $\mathrm{BO}$, digested with several restriction endonucleases and used as template for an outward PCR with primers deduced from the BiPBO1 integrase gene. Sequencing of $\sim 700 \mathrm{bp}$ and $\sim 1.2 \mathrm{~kb}$ PCR amplicons obtained by use of the restriction endonucleases DpnI and Eco32I, respectively, revealed the same transition point from the $\mathrm{BiPBO} 1$ prophage to the $\mathrm{BO} 1$ chromosome. The phage DNA was inserted adjacent to a gene for a lysine tRNA. Exactly the same integration site was found in the lysogenized B. abortus strain S19 (Figure 6). With the help of primers derived from the integration locus of the Brucella strain and the BiPBO1 genome, both borders of the integrated prophage were analyzed by sequencing of PCR products (data not shown). We found almost identical $48 \mathrm{bp}$ DNA sequences in the host and the phage DNA, which probably represent the attB and attP sites, respectively. The $46 \mathrm{bp}$ core sequence exists in a large number of Brucella and Ochrobactrum strains and in Liberibacter crescens (Leonard et al., 2012). Additionally, other members of the order rhizobiales (i.e., Rhizobium sp. Neorhizobium sp., Agrobacterium tumefaciens, Nitrobacter sp., Bartonella sp., and Oligotropha sp.) contain this sequence, each with a single nucleotide exchange (data not shown). A Multiplex-PCR system was developed to determine, whether this site is a hot spot for phage integration 
TABLE 2 | Host range of BiPBO1.

\begin{tabular}{|c|c|c|c|c|}
\hline Brucella strains & Biovar (bv) & $\mathbf{F 1}$ & F25 & BiPBO1 \\
\hline B. abortus & & + & + & + \\
\hline S19 & & + & + & + \\
\hline 544 & bv 1 & + & + & + \\
\hline 86/8/59 & bv 2 & + & + & + \\
\hline Tulya & bv 3 & + & + & + \\
\hline 292 & bv 4 & + & + & + \\
\hline B3196 & bv 5 & + & + & + \\
\hline 870 & bv 6 & + & + & + \\
\hline $63 / 75$ & bv 7 & + & + & + \\
\hline C68 & bv 9 & + & + & + \\
\hline B. melitensis & & - & - & \pm \\
\hline $16 \mathrm{M}$ & bv 1 & - & - & + \\
\hline $63 / 9$ & bv 2 & - & - & $\mathrm{Gl}$ \\
\hline Ether & bv 3 & - & - & + \\
\hline B. suis & & \pm & \pm & \pm \\
\hline 1330 & bv 1 & + & + & + \\
\hline Thomsen & bv 2 & Gl & $\mathrm{Gl}$ & - \\
\hline 686 & bv 3 & - & - & - \\
\hline 40 & bv 4 & + & + & + \\
\hline 513 & bv 5 & + & $\mathrm{Gl}$ & + \\
\hline B. canis & & - & - & - \\
\hline RM 6/66 & & - & - & - \\
\hline B. neotomae & & + & + & - \\
\hline $5 \mathrm{~K} 33$ & & + & + & Gl \\
\hline B. ovis & & - & - & - \\
\hline $63 / 290$ & & - & - & - \\
\hline B. ceti & & - & - & - \\
\hline B1/94 & & $\mathrm{Gl}$ & $\mathrm{Gl}$ & - \\
\hline B. pinnipedialis & & - & - & + \\
\hline B2/94 & & $\mathrm{Gl}$ & - & + \\
\hline B. microti & & + & + & + \\
\hline CCM 4915 T & & + & + & + \\
\hline B. inopinata & & - & - & - \\
\hline $\mathrm{BO} 1$ & & - & $\mathrm{Gl}$ & - \\
\hline Brucella sp. (novel) & & + & + & + \\
\hline F60 & & + & + & + \\
\hline F965 & & + & + & + \\
\hline
\end{tabular}

+, Iysis; -, no lysis; Gl, growth inhibition (no propagation of the phage).

(see Section Materials and Methods). However, in none of the investigated Brucella reference and type strains, a prophage was detected at this locus. This does not inevitably mean that BiPBO1 related sequences do not occur in other brucellae. Therefore, the strains were also investigated for the presence of BiPBO1-related sequences (genes for the integrase, the major capsid protein, and a replication protein). Similarly to the experiment before, no PCR amplicons were obtained with the selected primers indicating that BiPBO1-like prophages are rare in Brucella (data not shown).

Using the Micronaut ${ }^{\mathrm{TM}}$ system (Merlin Diagnostika $\mathrm{GmbH}$, Germany) phenotypic properties of B. abortus S19 and its lysogenic derivative were compared. We did not detect any differences between these strains. Hence, integration of BiPBO1

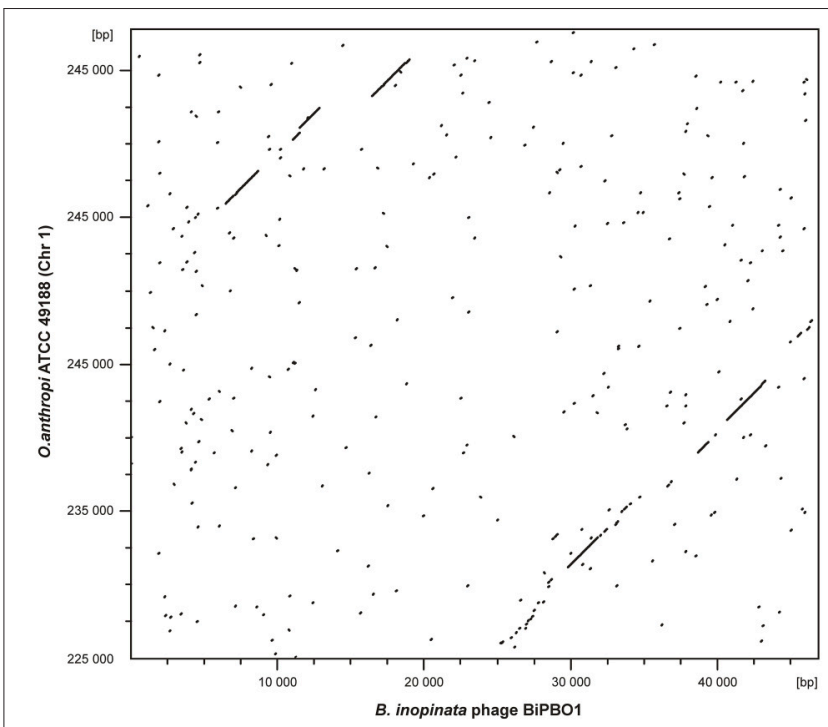

FIGURE 4 | Dot plot matrices of bacteriophage BiPBO1 with the Ochrobactrum anthropi ATCC 49188 chromosome 1. The axes of abscissas and ordinates indicate the coordinates of the respective genomes. Nucleotide alignments were performed with DS Gene (version 2.5) by using $65 \%$ as a standard parameter for DNA similarity and a hash value of 6 .

into the S19 chromosome does apparently not affect the metabolization of various substrates.

\section{DISCUSSION}

Only little is known about mobile genetic elements of Brucella which is an important zoonotic pathogen. Indeed, while some genomic islands have been identified in this genus (Delrue et al., 2004) and while virulent phages are routinely used for typing (Ackermann et al., 1981; Corbel, 1987; Hammerl et al., 2014), there are no reports yet on plasmids and temperate phages that may be involved in horizontal gene transfer. Even though some phages have been isolated from Brucella cultures (Corbel and Thomas, 1976; Los and Wegrzyn, 2012), lysogeny has not yet been demonstrated thus far. Since bioinformatic analyses of the hitherto sequenced Brucella phages did not reveal any prophage repressor genes (Flores et al., 2012; Farlow et al., 2014; Hammerl et al., 2014), association of the bacteria with these phages may represent a kind of pseudolysogeny (Los and Wegrzyn, 2012).

In this study, the first temperate Brucella phage has been characterized. Phage BiPBO1 isolated from B. inopinata is a siphovirus and therefore morphologically different from all known virulent Brucella phages, which belong to the family Podoviridae (Ackermann et al., 1981; Corbel, 1987; Rigby et al., 1989). Temperate phages might be more common in Brucella than previously expected. We detected prophage DNA in many Brucella strains in silico but failed to isolate further phages. Considering the lengths of most of the prophage sequences it is likely that they do not encode all proteins required for the assembly of intact particles. The Marinomonas phage P12026 e.g., possesses a genome of $31.7 \mathrm{~kb}$ (Kang et al., 2012) but 


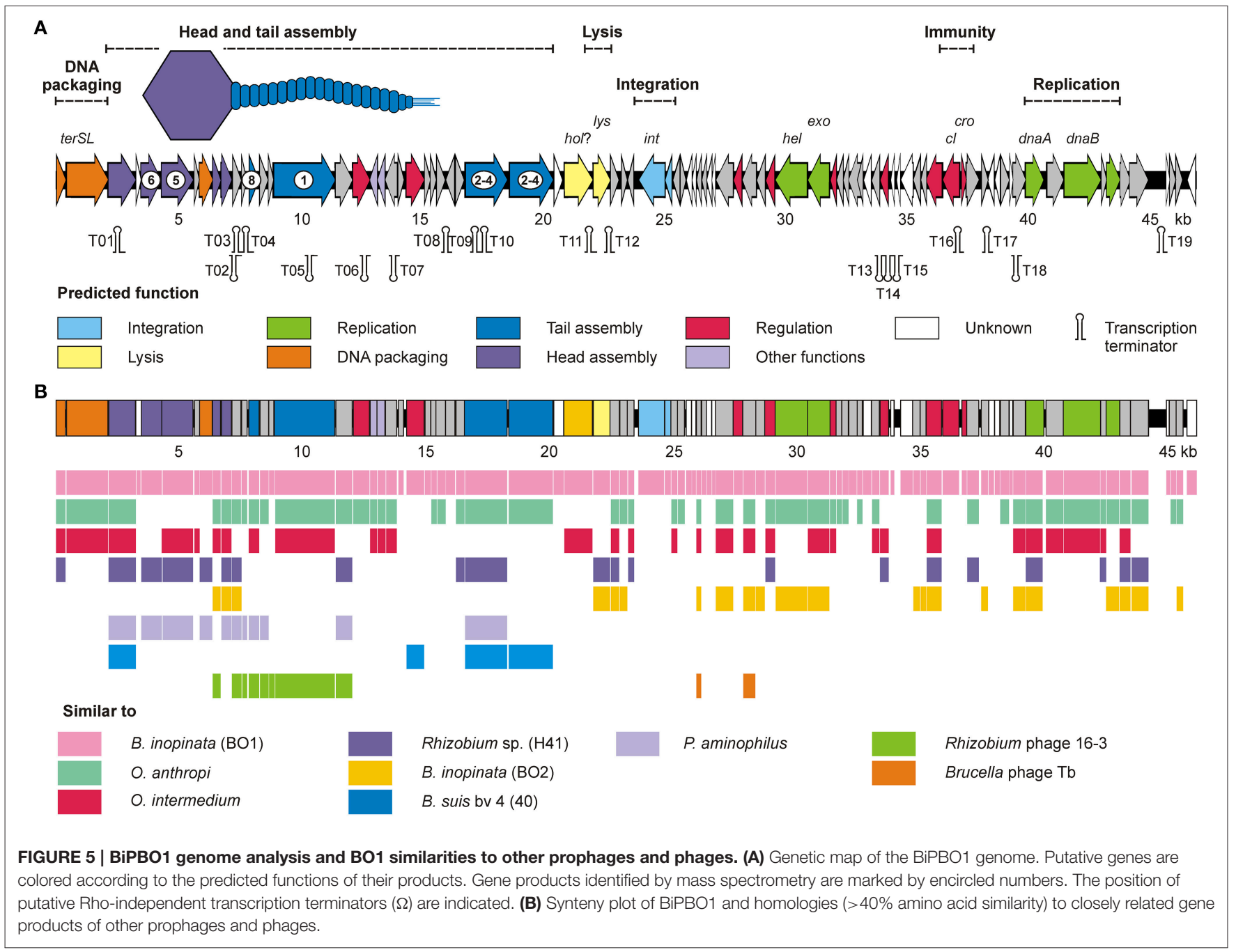

homologous sequences in Brucella have only a length of up to $13.7 \mathrm{~kb}$ (Table 1). It can of course not be ruled out that in some cases we did not use suitable indicator strains for the detection of lytic activity. This particularly pertains to a rather conserved prophage that has been detected in B. suis 1330 and many other brucellae. It is conceivable that the prophage repressor gene of this phage prevents cell lysis by closely related phages. On the other hand, it should be emphasized that the used computer program (Zhou et al., 2011) did not detect the BiPBO1 prophage in its natural host. The reason for this failure might be that only partial sequences of $B$. inopinata $\mathrm{BO} 1$ could be analyzed. However, some prophages might be more critical than others to be identified by in silico studies.

In spite of the fact that BiPBO1 was exclusively detected in the $B$. inopinata strain $\mathrm{BO}$, the phage exhibited a rather wide host range within the genus Brucella. Moreover, lysogenization of $B$. abortus $S 19$ was simply achieved and the prophage revealed a high stability in this strain and also in its original host. As the $\mathrm{BiPBO} 1$ attachment site is present in many brucellae and in other members of the rhizobiales, lysogenization of other species should be possible. Hence, the question arises why this phage was not found in more strains. The answer to this question could be the different habitats of brucellae. B. inopinata was isolated from a human breast implant infection and represents the most distant Brucella species at the phenotypic and phylogenetic level while it is closely related to Ochrobactrum (Scholz et al., 2010; Jimenéz de Bagüés et al., 2014). The animal or environmental reservoir of $B$. inopinata is not known but interestingly a closely related prophage exists in O. anthropi ATCC 49188 (Figure 4). We also analyzed this strain and found that it harbors six putative prophages. Upon induction with mitomycin C, phage particles exhibiting different morphologies (myoviral and siphoviral) were released from the cells (data not shown). Furthermore, the BiPBO1-related phage was isolated and characterized. Like $\mathrm{BiPB} 01$, this phage is a siphovirus, which, however, lysed several Ochrobactrum species, but not Brucella. Thus, these closely related phages presumably possess different receptor binding proteins determining host specificity. Nevertheless, the data suggest that at least in the past, mobile genetic elements were exchanged between these species and that phages released from $B$. inopinata did yet obviously not encounter other suitable Brucella hosts. Atypical Brucella species like B. inopinata may 


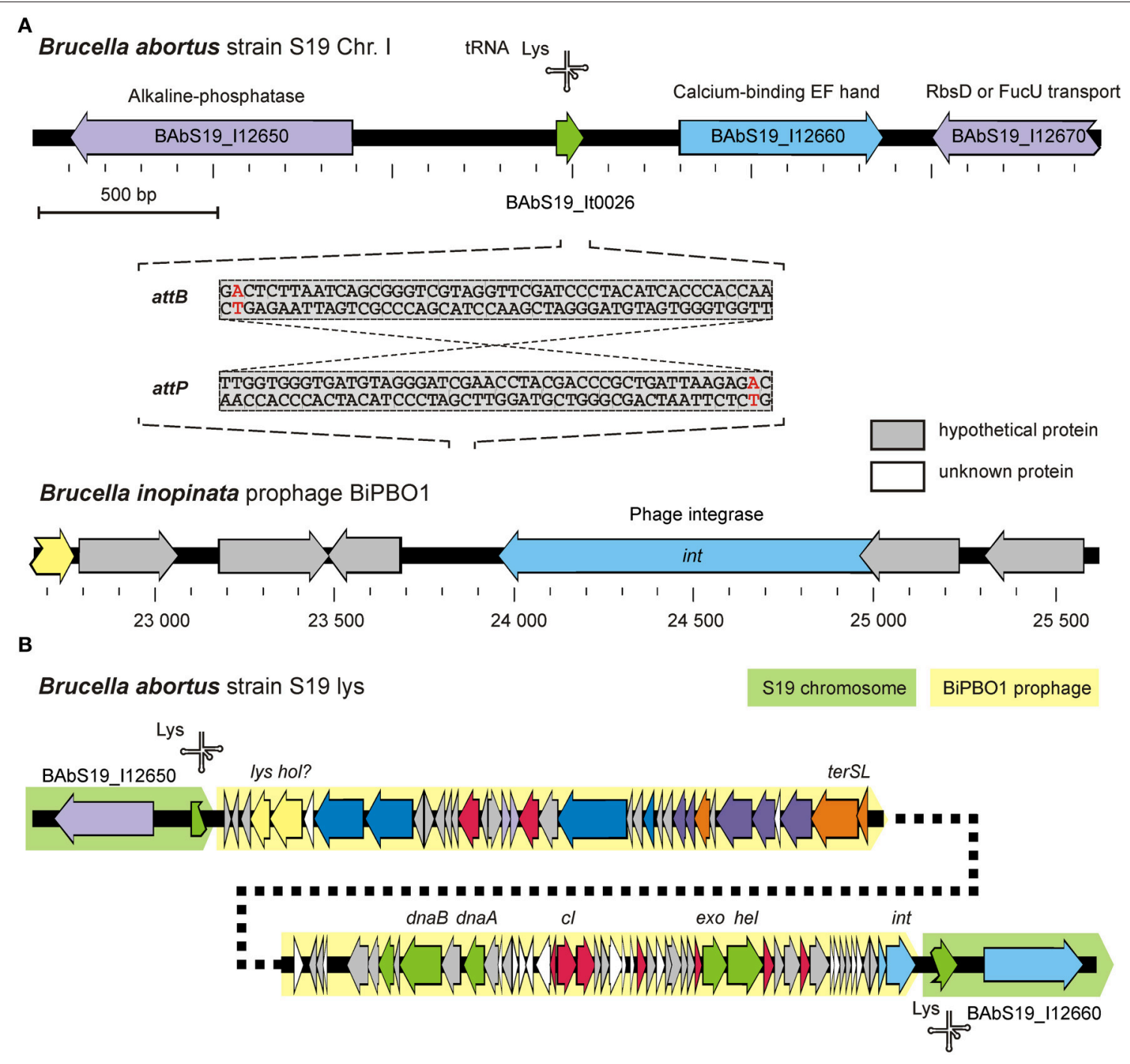

FIGURE 6 | Determination of BiPBO1 chromosomal integration. (A) Scheme of the genomic regions of $B$. abortus S19 and BiPBO1 involved in phage integration. attB and attP sequences of $\mathrm{S} 19$ and BiPBO1, respectively, are given. The red nucleotide within each sequence shows the single nucleotide deviation. (B) Structure of the BiPBO1 prophage in the lysogenized B. abortus S19 strain.

therefore represent a link between classical Brucella species and Ochrobactrum and other rhizobiales (Wattam et al., 2014). Phages released from these environmental bacteria might enter classical Brucella strains by an intermediate propagation in atypical brucellae. On the other hand, the $1.5 \mathrm{~kb}$ DNA region in many Brucella strains that revealed strong homologies to parts of the BiPB01 ORFs 29 and 30 and that is located adjacent to the attachment site B might be a remnant of a former prophage, which was deleted in the course of genome reduction during the evolution from a soil bacterium to a pathogen.

The BiPBO1 genome has a size of $46.9 \mathrm{~kb}$ which lies within the common size range of temperate phages. Most BiPBO1 gene products did not disclose similarities to proteins of other phages. Homologies were rather found to hypothetical proteins encoded by predicted prophages residing in various genera, notably Ochrobactrum. Nevertheless, some presumably essential genes have been identified. According to the determined data the BiPBO1 genome is similarly organized like the genomes of many other temperate phages. Genes important for virion assembly, integration, replication and host cell lysis are more or less clustered. Though, due to the large number of genes with unknown functions, this impression might change when more information is available on the phage proteins with yet unknown function. Similarly, it can currently not be excluded that BiPBO1 contains genes that cause a lysogenic conversion of the host. Integration of the phage into the bacterial chromosome was not observed within the coding sequence of a gene and we did not detect any metabolic changes in the lysogenized B. abortus strain S19. However, other phenotypic properties of the bacteria, e.g., the ability to invade and replicate within cells might be affected. This has to be investigated by further comparison of lysogenic and non-lysogenic strains. 
In conclusion, this study showed that temperate phages exist in Brucella. To what extent they are involved in horizontal gene transfer has still to be clarified. Nevertheless, the close relationship of $B$. inopinata phage BiPBO1 to an O. anthropi phage suggests that gene exchange may occur between these genera. Unfortunately, no information is currently available on temperate phages of Ochrobactrum. Our analysis of O. anthropi ATCC 49188 shows that they occur in this genus. Hence, it makes sense to study more phages of Brucella and Ochrobactrum to gain insight into the role that they play for these bacteria.

\section{AUTHOR CONTRIBUTIONS}

$\mathrm{JH}, \mathrm{SH}, \mathrm{KN}$, and SA designed the study. JH, CG, and JR performed the experiments. JH, CG, JR, KN, SA analyzed the

\section{REFERENCES}

Abedon, S. T. (2011). Lysis from without. Bacteriophage 1, 46-49. doi: 10.4161/bact.1.1.13980

Ackermann, H. W., Simon, F., and Verger, J. M. (1981). A survey of Brucella phages and morphology of new isolates. Intervirology 16, 1-7. doi: 10.1159/000149240

Al Dahouk, S., Hofer, E., Tomaso, H., Vergnaud, G., Le Flèche, P., Cloeckaert, A., et al. (2012). Intraspecies biodiversity of the genetically homologous species Brucella microti. Appl. Environ. Microbiol. 78, 1534-1543. doi: 10.1128/AEM.06351-11

Al Dahouk, S., Scholz, H. C., Tomaso, H., Bahn, P., Göllner, C., Karges, W., et al. (2010). Differential phenotyping of Brucella species using a newly developed semi-automated metabolic system. BMC Microbiol. 10:269. doi: 10.1186/14712180-10-269

Allison, G. E., Angeles, D., Tran-Dinh, N., and Verma, N. K. (2002). Complete genomic sequence of $\mathrm{SfV}$, a serotype-converting temperate bacteriophage of Shigella flexneri. J. Bacteriol. 184, 1974-1987. doi: 10.1128/JB.184.7.19741987.2002

Alton, G. G., Jones, L. M., and Pietz, D. E. (1975). Laboratory Techniques in Brucellosis. Geneva: World Health Organization.

Aziz, R. K., Bartels, D., Best, A. A., DeJongh, M., Disz, T., Edwards, R. A., et al. (2008). The RAST Server: rapid annotations using subsystems technology. BMC Genomics 9:75. doi: 10.1186/1471-2164-9-75

Boyd, E. F., and Brüssow, H. (2002). Common themes among bacteriophageencoded virulence factors and diversity among the bacteriophages involved. Trends Microbiol. 10, 521-529. doi: 10.1016/S0966-842X(02)02459-9

Brown, C. M., Dalphin, M. E., Stockwell, P. A., and Tate, W. P. (1993). The translational termination signal database. Nucleic Acids Res. 21, 3119-3123. doi: 10.1093/nar/21.13.3119

Brown-Jaque, M., Calero-Cáceres, W., and Muniesa, M. (2015). Transfer of antibiotic-resistance genes via phage-related mobile elements. Plasmid 79, 1-7. doi: 10.1016/j.plasmid.2015.01.001

Brüssow, H., Canchaya, C., and Hardt, W. D. (2004). Phages and the evolution of bacterial pathogens: from genomic rearrangements to lysogenic conversion. Microbiol. Mol. Biol. Rev. 68, 560-602. doi: 10.1128/MMBR.68.3.560-602.2004

Canchaya, C., Fournous, G., and Brüssow, H. (2004). The impact of prophages on bacterial chromosomes. Mol. Microbiol. 53, 9-18. doi: 10.1111/j.13652958.2004.04113.x

Casas, V., and Maloy, S. (2011). Role of bacteriophage-encoded exotoxins in the evolution of bacterial pathogens. Future Microbiol. 6, 1461-1473. doi: $10.2217 /$ fmb.11.124

Casjens, S. (2003). Prophages and bacterial genomics: what have we learned so far? Mol. Microbiol. 49, 277-300. doi: 10.1046/j.1365-2958.2003.03580.x

Corbel, M. J. (1987). Brucella phages: advances in the development of a reliable phage typing system for smooth and non-smooth Brucella isolates. Ann. Inst. Pasteur Microbiol. 138, 70-75. doi: 10.1016/0769-2609(87)90056-1 data. All authors prepared the tables and figures, wrote and edited the manuscript.

\section{ACKNOWLEDGMENTS}

The authors thank Peter Bahn and Anna-Louisa Hauffe, from the Federal Institute for Risk Assessment, for excellent technical assistance. The work was supported by the BfR (grant no. 47-002 and 1322-503).

\section{SUPPLEMENTARY MATERIAL}

The Supplementary Material for this article can be found online at: http://journal.frontiersin.org/article/10.3389/fmicb. 2016.00024

Corbel, M. J., and Phillip, J. I. (1972). The relationship of Brucella abortus agglutinogenic antigens to the receptor sites for Tbilisi phage. Res. Vet. Sci. 13, 91-93.

Corbel, M. J., and Thomas, E. L. (1976). Properties of some new Brucella phage isolates; evidence for lysogeny within the genus. Dev. Biol. Stand. 31, 38-45.

Delrue, R. M., Lestrate, P., Tibor, A., Letesson, J. J., and De Bolle, B. (2004). Brucella pathogenesis, genes identified from random large-scale screens. FEMS Microbiol. Lett. 231, 1-12. doi: 10.1016/S0378-1097(03)00963-7

Ermolaeva, M. D., Khalak, H. G., White, O., Smith, H. O., and Salzberg, S. L. (2000). Prediction of transcription terminators in bacterial genomes. J. Mol. Biol. 301, 27-33. doi: 10.1006/jmbi.2000.3836

Farlow, J., Filippov, A. A., Sergueev, K. V., Hang, J., Kotorashvili, A., and Nikolich, M. P. (2014). Comparative whole genome analysis of six diagnostic brucellaphages. Gene 541, 115-122. doi: 10.1016/j.gene.2014.01.018

Flores, V., López-Merino, A., Mendoza-Hernandez, G., and Guarneros, G. (2012). Comparative genomic analysis of two brucellaphages of distant origins. Genomics 99, 233-240. doi: 10.1016/j.ygeno.2012.01.001

Fortier, L. C., and Sekulovic, O. (2013). Importance of prophages to evolution and virulence of bacterial pathogens. Virulence 4, 354-365. doi: 10.4161/viru.24498

Fraser, J. S., Yu, Z., Maxwell, K. L., and Davidson, A. R. (2006). Ig-like domains on bacteriophages: a tale of promiscuity and deceit. J. Mol. Biol. 359, 496-507. doi: 10.1016/j.jmb.2006.03.043

Glass, E. M., Wilkening, J., Wilke, A., Antonopoulos, D., and Meyer, F. (2010). Using the metagenomics RAST server (MG-RAST) for analyzing shotgun metagenomes. Cold Spring Harb. Protoc. 2010:pdb.prot5368. doi: $10.1101 /$ pdb.prot5368

Godfroid, J., Al Dahouk, S., Pappas, G., Roth, F., Matope, G., Muma, J., et al. (2012). A "One Health" surveillance and control of brucellosis in developing countries: moving away from improvisation. Comp. Immunol. Microbiol. Infect. Dis. 36, 241-248. doi: 10.1016/j.cimid.2012.09.001

Hammerl, J. A., Al Dahouk, S., Nöckler, K., Göllner, C., Appel, B., and Hertwig, S. (2014). F1 and tbilisi are closely related brucellaphages exhibiting some distinct nucleotide variations which determine the host specificity. Genome Announc. 2:e01250-13. doi: 10.1128/genomeA.01250-13

Hammerl, J. A., Jäckel, C., Reetz, J., Beck, S., Alter, T., Lurz, R., et al. (2011). Campylobacter jejuni group III phage CP81 contains many T4-like genes without belonging to the T4-type phage group: implications for the evolution of T4 phages. J. Virol. 85, 8597-8605. doi: 10.1128/JVI.00395-11

Hammerl, J. A., Klein, I., Lanka, E., Appel, B., and Hertwig, S. (2008). Genetic and functional properties of the self-transmissible Yersinia enterocolitica plasmid pYE854, which mobilizes the virulence plasmid pYV. J. Bacteriol. 190, 991-1010. doi: 10.1128/JB.01467-07

Hammerl, J. A., Ulrich, R. G., Imholt, C., Scholz, H. C., Jacob, J., Kratzmann, N., et al. (2015). Molecular survey on brucellosis in rodents and shrews - natural reservoirs of novel Brucella species in Germany? Transbound. Emerg. Dis. doi: 10.1111/tbed.12425. [Epub ahead of print]. 
Hatfull, G. F. (2008). Bacteriophage genomics. Curr. Opin. Microbiol. 11, 447-453. doi: 10.1016/j.mib.2008.09.004

Hugouvieux-Cotte-Pattat, N., Condemine, G., and Shevchik, V. E. (2012). Bacterial pectate lyases, structural and functional diversity. Environ. Microbiol. Rep. 6, 427-440. doi: 10.1111/1758-2229.12166

Iguchi, A., Iyoda, S., Terajima, J., Watanabe, H., and Osawa, R. (2006). Spontaneous recombination between homologous prophage regions causes large-scale inversions within the Escherichia coli O157, H7 chromosome. Gene 372, 199-207. doi: 10.1016/j.gene.2006.01.005

Jimenéz de Bagüés, M. P., Iturralde, M., Arias, M. A., Pardo, J., Cloeckaert, A., and Zygmunt, M. S. (2014). The new strains Brucella inopinata BO1 and Brucella species 83-210 behave biologically like classic infectious Brucella species and cause death in murine models of infection. J. Infect. Dis. 210, 467-472. doi: 10.1093/infdis/jiu102

Johnson, M., Zaretskaya, I., Raytselis, Y., Merezhuk, Y., McGinnis, S., and Madden, T. L. (2008). NCBI BLAST: a better web interface. Nucleic Acids Res. 36, W5-W9. doi: 10.1093/nar/gkn201

Kaden, R., ågren, J., Båverud, V., Hallgren, G., Ferrari, S., Börjesson, J., et al. (2014a). Brucellosis outbreak in a Swedish kennel in 2013, Determination of genetic markers for source tracing. Vet. Microbiol. 174, 523-530. doi: 10.1016/j.vetmic.2014.10.015

Kaden, R., Agren, J., Ferrari, S., Lindberg, M., Backman, S., and Wahab, T. (2014b). Whole-genome sequence of Brucella canis strain SVA13, isolated from an infected dog. Genome Announc. 2:e00700-14. doi: 10.1128/genomea.00700-14

Kang, I., Jang, H., Oh, H. M., and Cho, J. C. (2012). Complete genome sequence of Marinomonas bacteriophage P12026. J. Virol. 86, 8909-8910. doi: 10.1128/JVI.01328-12

Kropinski, A. M. (2000). Sequence of the genome of the temperate, serotypeconverting, Pseudomonas aeruginosa bacteriophage D3. J. Bacteriol. 182, 6066-6074. doi: 10.1128/JB.182.21.6066-6074.2000

Leonard, M. T., Fagen, J. R., Davis-Richardson, A. G., Davis, M. J., and Triplett, E. W. (2012). Complete genome sequence of Liberibacter crescens BT-1. Stand. Genomic Sci. 7, 271-283. doi: 10.4056/sigs.3326772

Los, M., and Wegrzyn, G. (2012). Pseudolysogeny. Adv. Virus Res. 82, 339-349. doi: 10.1016/B978-0-12-394621-8.00019-4

Meyer, F., Paarmann, D., D’Souza, M., Olson, R., Glass, E. M., Kubal, M., et al. (2008). The metagenomics RAST server - a public resource for the automatic phylogenetic and functional analysis of metagenomes. BMC Bioinformatics 9:386. doi: 10.1186/1471-2105-9-386

Naville, M., Ghuillot-Gaudeffroy, A., Marchais, A., and Gautheret, D. (2011). ARNold: a web tool for the prediction of Rho-independent transcription terminators. RNA Biol. 8, 11-13. doi: 10.4161/rna.8.1.13346

Paulsen, I. T., Seshadri, R., Nelson, K. E., Eisen, J. A., Heidelberg, J. F., Read, T. D., et al. (2002). The Brucella suis genome reveals fundamental similarities between animal and plant pathogens and symbionts. Proc. Natl. Acad. Sci. U.S.A. 99, 13148-13153. doi: 10.1073/pnas.192319099

Penadés, J. R., Chen, J., Quiles-Puchalt, N., Carpena, N., and Novick, R. P. (2015). Bacteriophage-mediated spread of bacterial virulence genes. Curr. Opin. Microbiol. 23, 171-178. doi: 10.1016/j.mib.2014.11.019

Prestel, E., Salamitou, S., and DuBow, M. S. (2008). An examination of the bacteriophages and bacteria of the Namib desert. J. Microbiol. 46, 364-372. doi: 10.1007/s12275-008-0007-4

Rigby, C. E., Cerqueira-Campos, M. L., Kelly, H. A., and Surujballi, O. P. (1989). Properties and partial genetic characterization of Nepean phage and other lytic phages of Brucella species. Can. J. Vet. Res. 53, 319-325.

Rombel, I. T., Sykes, K. F., Rayner, S., and Johnston, S. A. (2002). ORFFINDER: a vector for high-throughput gene identification. Gene 282, 33-41. doi: 10.1016/S0378-1119(01)00819-8
Sambrook, J., and Russel, D. (2001). Molecular Cloning: A Laboratory Manual. New York, NY: Cold Spring Harbor.

Scholz, H. C., Al Dahouk, S., Tomaso, H., Neubauer, H., Witte, A., Schloter, M., et al. (2008). Genetic diversity and phylogenetic relationships of bacteria belonging to the Ochrobactrum-Brucella group by recA and 16S rRNA genebased comparative sequence analysis. Syst. Appl. Microbiol. 31, 1-16. doi: 10.1016/j.syapm.2007.10.004

Scholz, H. C., Nöckler, K., Göllner, C., Bahn, P., Vergnaud, G., Tomaso, H., et al. (2010). Brucella inopinata sp. nov., isolated from a breast implant infection. Int. J. Syst. Evol. Microbiol. 60, 801-808. doi: 10.1099/ijs.0.011148-0

Srinivasiah, S., Bhavsar, J., Thapar, K., Liles, M., Schoenfeld, T., and Wommack, K. E. (2008). Phages across the biosphere: contrasts of viruses in soil and aquatic environments. Res. Microbiol. 159, 349-357. doi: 10.1016/j.resmic.2008.04.010

Teyssier, C., Marchandin, H., and Jumas-Bilak, E. (2004). The genome of alphaproteobacteria: complexity, reduction, diversity and fluidity. Can. J. Microbiol. 50, 383-396. doi: 10.1139/w04-033

Thomas, E. L., and Corbel, M. J. (1977). Isolation of a phage lytic for several Brucella species following propagation of Tbilisi phage in the presence of mitomycin C. Arch. Virol. 54, 259-261. doi: 10.1007/BF01314793

Viazis, S., Akhtar, M., Feirtag, J., Brabban, A. D., and Diez-Gonzalez, F. (2011). Isolation and characterization of lytic bacteriophages against enterohaemorrhagic Escherichia coli. J. Appl. Microbiol. 110, 1323-1331. doi: 10.1111/j.1365-2672.2011.04989.x

Wang, L., Xue, J., Seaborn, C. P., Arif, B. M., and Cheng, X. W. (2006). Sequence and organization of the Trichoplusia ni ascovirus 2c (Ascoviridae) genome. Virology 354, 167-177. doi: 10.1016/j.virol.2006.06.029

Wattam, A. R., Foster, J. T., Mane, S. P., Beckstrom-Sternberg, S. M., BeckstromSternberg, J. M., Dickerman, A. W., et al. (2014). Comparative phylogenomics and evolution of the brucellae reveal a path to virulence. J. Bacteriol. 196, 920-930. doi: 10.1128/JB.01091-13

Wommack, K. E., and Colwell, R. R. (2000). Virioplankton: viruses in aquatic ecosystems. Microbiol. Mol. Biol. Rev. 64, 69-114. doi: 10.1128/MMBR.64.1.69114.2000

Yoosuf, N., Yutin, N., Colson, P., Shabalina, S. A., Pagnier, I., Robert, C., et al. (2012). Related giant viruses in distant locations and different habitats: Acanthamoeba polyphaga moumouvirus represents a third lineage of the Mimiviridae that is close to the megavirus lineage. Genome Biol. Evol. 4, 1324-1330. doi: 10.1093/gbe/evs109

Zhang, Y., and Jiao, N. (2009). Roseophage RDJL Phil, infecting the aerobic anoxygenic phototrophic bacterium Roseobacter denitrificans OCh114. Appl. Environ. Microbiol. 75, 1745-1749. doi: 10.1128/AEM.02131-08

Zheludkov, M. M., and Tsirelson, L. E. (2013). Reservoirs of Brucella infection in nature. Biol. Bull. 37, 709-715. doi: 10.1134/S106235901007006X

Zhou, Y., Liang, Y., Lynch, K. H., Dennis, J. J., and Wishart, D. S. (2011). PHAST: a fast phage search tool. Nucleic Acids Res. 39, W347-W352. doi: $10.1093 /$ nar/gkr485

Conflict of Interest Statement: The authors declare that the research was conducted in the absence of any commercial or financial relationships that could be construed as a potential conflict of interest.

Copyright (c) 2016 Hammerl, Göllner, Al Dahouk, Nöckler, Reetz and Hertwig. This is an open-access article distributed under the terms of the Creative Commons Attribution License (CC BY). The use, distribution or reproduction in other forums is permitted, provided the original author(s) or licensor are credited and that the original publication in this journal is cited, in accordance with accepted academic practice. No use, distribution or reproduction is permitted which does not comply with these terms. 